\title{
Nurses/Midwifery Trainees' Knowledge, Attitudes and Utilisation of HIV Testing/Counselling Service in the Central Region of Ghana
}

\author{
Francis Sambah ${ }^{1}$, Thomas Hormenu ${ }^{1}$, Bright Opoku Ahinkorah ${ }^{1}$, John Elvis Hagan Jr ${ }^{1,2}$ and Thomas Schack $^{2}$ \\ 1. Department of Health, Physical Education and Recreation, University of Cape Coast, Private Mail Bag, Cape Coast, Ghana \\ 2. Neurocognition and Action-Biomechanics-Research Group, Faculty of Psychology and Sport Sciences, Bielefeld University,
}

Bielefeld, 33501, Germany

\begin{abstract}
Background and purpose: Despite HIV testing and counselling (HTC) being recognized as important elements of any effective prevention, detection, care, and management programmes across many societies as part of their primary health care package, it is surprising that research evidence on related issues, especially in developing countries like Ghana is sparse. This study examined the extent of knowledge, attitudes and utilisation of HIV testing, and counselling services among trainee nurses of the public nursing and midwifery training colleges in the Central Region of Ghana. Methods and results: A descriptive cross-sectional design was employed to collect data from 375 nursing and midwifery students using multistage sampling procedures. Findings showed that students' HTC knowledge was high (85\%) whereas attitudes toward HTC were rated positive (95\%). However, HTC utilisation was low (47\%). Further results revealed a statistically significant difference between class level and HTC utilisation $\left(\chi^{2}[1, N=375]=\right.$ 14.263, $p=0.000$ ). In contrast, no statistically significant differences in student nurses' class level and HTC knowledge $\left(\chi^{2}[1, N=\right.$ $375]=0.624, p=0.475)$ as well as class level and attitudes toward HTC services $\left(\chi^{2}[1, N=375]=2.334, p=0.158\right)$ were realized. Conclusion: The low HTC utilisation among the student nurses may potentially lead to missing opportunities for early diagnoses, care, treatment, and support services for primary, secondary or tertiary prevention modes. Organisation of programmes by college authorities on the importance of HTC and the need for student nurses to utilise these services is crucial.
\end{abstract}

Key words: HTC, knowledge, attitude, utilisation, nurses, midwives, Ghana.

\section{Introduction}

Since the first human immunodeficiency virus/acquired immune deficiency syndrome (HIV/AIDS) case was diagnosed over two decades ago, the disease has caused serious humanitarian and developmental challenges [1]. HIV/AIDS has become a global public health concern [2], threatening the well-being of so many nations of the world. Globally, about 36.7 million people are living with HIV/AIDS, with Sub-Saharan Africa being the region heavily affected, causing many deaths since the disease was identified in the region $[3,4]$. For example, since the medical

Corresponding author: John Elvis Hagan Jr., Ph.D, research fields: sport and exercise psychology, health education and promotion. diagnoses of the HIV/AIDS in Ghana in 1986, the disease has become endemic in the country, infecting and affecting all age groups and disrupting the Ghanaian hospitality industry [5]. The Ghana AIDS Commission report [6] indicates that the epidemic in Ghana stands at a prevalence of more than $1 \%$ in the general population [7]. The 2015 GAC report further reveals that the prevalence has somewhat plateaued between 2012 and 2014, with national prevalence figures as $1.37 \%, 1.3 \%$, and $1.47 \%$ respectively. The 2016 prevalence rate dropped to $1.37 \%$ but still above the World Health Organisation (WHO) safety prevalence indicator (1.0) which is still a health concern.

The economic impact in Ghana is worrying as developmental resources are channeled into Anti-Retroviral Therapy (ART) drugs, other materials, 
and financial aids to these patients and orphans. The estimated number of AIDS patients needing ART increased from 127,306 in 2013 to 142,164 in 2014. Of these figures, 8,732 and 8,582 respectively were children. Similarly, out of the 133,582 adults administered ART in 2014, 49,267 (males) and 84,315 (females) were identified. A snapshot of expenditure from 2011 to 2015 AIDS related services was US $\$ 443,863,268$, increasing from US\$59.7 million in 2011 to US\$104.3 million in 2015. Despite these investments, evidence suggests that a funding gap totaling US\$31, 277 for the 2015 and 2016 administrative years still remains [7].

The current situation clearly demands urgent prevention and control measures in the country. One measure under discussion is the widespread introduction of voluntary HIV testing and counselling (HTC) across the country. According to SADC [8], HTC is the processes by which people seek voluntary services to enable them make informed choices after learning about their status and taking appropriate actions. The processes consist of pre-test, post-test and follow-up counselling. The procedure of discovering one's HIV status, regardless of the test result, is an opportunity for education and motivation to modify behavior targeted at reducing the risk of HIV transmission [9]. For those infected with HIV, HTC provides a means of accessing available HIV care services such as further counselling support, preventive therapy against opportunistic infections and antiretroviral therapy (ART). Since the inception of voluntary counselling and testing (VCT) in 1985, the concept has undergone various evaluations and meta-analysis to assess its efficacy in the primary and secondary prevention of HIV transmission and management [10-12], with evidence proven to be efficacious in the primary prevention, care and treatment of HIV/AIDS. For instance, findings from a randomized trial to determine the efficacy of HIV testing and counselling in reducing unprotected sexual intercourse among individuals and sex partners in three countries (Kenya,
Tanzania, and Trinidad) showed a drastic reduction in the proportion of individuals reporting unprotected sex with non-primary partners for participants receiving testing and counselling than those receiving health information. Specifically, 35\% reduction with testing/counselling as against $13 \%$ reduction with health information among men, and 39\% reduction with testing/counselling as against 175 reductions with health information among women were recorded [10]. Similarly, in a cohort study to examine the impact of HTC on self-reported risk behavior prior to and three months after HIV testing, HTC resulted in changes in some self-reported risk behavior such as decrease in the average number of sexual partners, use of alcohol with sex and episode of unprotected sex, though only among HIV positive subjects [13]. Other empirical evidence from ECDC [14] suggests that early diagnosis of HIV infection and eventual treatment can markedly improve prognosis for the individual who can expect low morbidity and enhance a good quality of life and a near normal life expectancy.

Research evidence from both developed and developing countries shows that HTC leads to earlier access to HIV therapy, which in turn increases its effectiveness and reduces risk behavior [15]. Despite this overwhelming evidence of HTC as a preventive, care and management tool for HIV/AIDS, sub-Saharan Africa including Ghana is still grappling with the adoption and utilisation of HTC services. A survey of HTC utilisation in 12 high-burden sub-Saharan African countries found that only 12\% (men) and 10\% (women) in the general population have both been tested for HIV and received their test results [16, 17]. Another report from the Southern Africa Development Community (SADC) showed that citizens' utilisation of the service has been low despite wide political adoption of HTC services in the region. A Ghana Demographic and Health Survey (GDHS) on the adoption rate of HTC found that although, about $70 \%$ of respondents know where to get an HIV test, 
only $21 \%$ females and $14 \%$ of males aged between 15-49 have undergone HTC services [18].

There are varied prerequisites for successful HTC programmes. Besides the need for clear protocols for counselling, testing, and treatment, there is also the need for: (a) awareness and knowledge of HIV in the community, (b) attitudes toward acceptability of HTC to potential recipients and to the health professionals who must administer it, and (c) willingness of health professionals to provide care, manage, and treat HIV positive individuals [19]. Therefore, nurses and midwives play a central role in the HTC services [20]. However, research has shown that refraining attitudes against HIV/AIDS and HTC are still present among health care personnel [21] and pre-service nurses [22-24]. Studies have also revealed that there is low knowledge about HIV/AIDS among health care workers and low uptake of HTC by student nurses [25-27]. Tarwireyi and Majoko [28] found that health workers were reluctant to have an HIV test, which inhibited their ability to initiate HTC services to clients. Pre-service nurses developing positive attitudes toward HTC will serve as positive role models in educating clients about HTC and HIV/AIDS services in their future occupational settings [25, 27]. To date, only few studies have explored HTC among college students' nurses [26, 29]. Due to the high prevalence of HIV/AIDS in some parts of the country, including the Central Region, the purpose of this study was to examine the knowledge level, attitudes and utilisation of HTC among trainee nurses of selected public nursing and midwifery training colleges in the Central Region of Ghana. This study is critical because it could help provide key baseline information for evaluating the effectiveness of strategies that may promote the prevention, care and management of HIV/AIDS.

\section{Materials and Methods}

\subsection{Participants'Selection Criteria}

Using a cross-sectional design, student nurses from level 200 and 300 from the five public nursing and midwifery training colleges in the Central Region of Ghana were chosen. A sample size of 375 was obtained based on Krejcie and Morgan [30] standardized table for determining sample size. This sample size was made up of 262 females and 113 males. The actual sample size from Krejcie and Morgans' table was 341 but was increased by $10 \%$ to make room for non-returnability and non-completion of questionnaires. A multistage sampling technique was employed comprising stratified random and simple random sampling to select the study participants. These methods were chosen in order to reduce selection bias and to ensure that the sample actually reflects the true characteristic of the entire population under study [31]. All study-related documents were reviewed and approved by the Institutional Review Board (IRB) at University of Cape Coast, Ghana (UCCIRB/CES/2016/04). Participants received written informed consent and were included in the study only after signing the informed consent forms. The signing was done after students were assured of their anonymity and confidentiality at all stages of the data collection process.

\subsection{Instrumentation}

A researcher generated questionnaire with developed questions was divided into 3 different segments (A, B, C); knowledge, attitudes to testing and counseling as well as utilization was used. All the items on the questionnaire had variables measured under the nominal and Likert scale. For demographic information (segment A), participants were asked about their gender, age, marital/relationship status, religious affiliation, and class level. Questions on knowledge were developed on the basis that knowledge is essential to informed choices about testing, with an item example such as "HIV/AIDS testing and counselling reduces the risk for acquiring HIV/AIDS” constituted segment B. For segment C, 
questions on attitudes were drawn specifically on personal reactions to HIV testing, willingness to disclose status, and reactions to a positive test and counseling service available to clients as well as varied utilisation items such as "want to know status". The draft questionnaire was piloted among 50 trainees from the Nursing and Midwifery Training College in the Damongo District of the Northern Region of Ghana. The pilot testing led to modifications being made. The internal consistency measure for the instrument yielded a reliability coefficient of Kuder-Richardson (KR-20) formula for Section B subscale in the pilot and main study as 0.62 and 0.75 while the Cronbach Alpha reliability coefficient for section $C$ subscale was 0.65 and 0.80 in the pilot and main study respectively. The KR-20 was chosen for Section B subscale because it is a reliability measure suitable for binary variables (i.e. answers that are right or wrong or yes or no). The scores for KR-20 ranged from 0 to 1 , where 0 is no reliability and 1 is perfect reliability. The closer the score is to 1 , the more reliable the test [32].

\subsection{Procedure}

After an initial permission was sought from the authorities and rapport established with student-leaders of the colleges, trainee nurses/midwifery students were approached while attending a social gathering organized by their respective institutions. We chose this platform because it represented an all-inclusive public access avenue in the colleges. Participants were approached by one of the researchers and a team of trained research assistants and were asked to voluntarily take a short time to answer an anonymous questionnaire. All potential participants present at the respective venues in their colleges were subsequently approached to participate. To avoid contextual influence, an introductory session was arranged to brief participants on the purpose of the study and the standard instructions needed for a completion of the questionnaire. All students who agreed to complete the survey were able to self-administer the questionnaire with minimal assistance. Three hundred and seventy-five (375) questionnaires were administered in all. The data collection process lasted over three weeks, with a $100 \%$ return rate.

\subsection{Data Analysis}

Data were analyzed in different stages using SPSS version 21. Pre-screening procedures were conducted to ensure the accuracy and appropriateness of the data. All statistical assumptions were subsequently tested. Furthermore, responses to knowledge questions were classified as correct or incorrect. Total scores were transformed to frequencies and percentages. A score of $\geq 70 \%$ was categorized as high knowledge, a score of $51-69 \%$ was considered moderate whereas $<50 \%$ was deemed low knowledge. Regarding attitudes toward HTC, study participants who had or were willing to have HTC or would recommend it to others were considered to have positive attitudes. Comparatively, those who were unwilling to have HTC or would not recommend it to others were regarded to have negative attitudes. For attitudes and utilization, similar percentage scores were determined. Significant differences on student' class level and HTC knowledge, attitudes and utilization were assessed with a univariate analysis, using the Chi-square test with continuity correction at an alpha level of 0.05 .

\section{Results}

\subsection{Background Characteristics}

Out of a total of 375 student nurses, females' representation constituted 70\% $(n=262)$ whereas 30\% ( $n=113)$ were males. Majority of the respondents were between the age category 21-23, representing $56 \%(n=210)$, while the age category, 24-26 represented 32\% ( $n=120)$ and 18-20 age group made up $6 \%(n=23)$. The least age representations in the study were of the age categories: $27-29,6 \%(n=18)$ and age $30+$ made up $1 \%(n=4)$. On 
marital/relationship status of the participants: $66 \%$ ( $n$ $=247)$ of trainees were single, $7 \%(n=17)$ were married, 29\% $(n=108)$ had boyfriend/girlfriend, and $1 \%(n=3)$ have separated/divorced from their former marriages. On religious affiliation, majority of students were Christians: $93 \%(n=347)$ followed by $6 \%$ $(n=23)$ Moslems, and $1 \%(n=5)$ were of other religions. The class level representation showed $46 \%$ $(n=173)$ for level 200 and 54\% $(n=202)$ for level 300.

3.1.1 Student Nurses' Knowledge Responses on HTC Service

Overall results in Table 1 show that majority of the respondents, $85 \%$ ( $n=317$ ) showed high knowledge of HTC.

The level of student nurses' knowledge on various items measuring HTC is shown in Table 2. The results in Table 2 show that the students' performance was high in terms of their knowledge scores on HTC issues. High performance on many of the items measuring HTC knowledge was noted correctly: 95\% ( $n=357$ ), indicating that HTC is for everybody, 93\% $(n=350)$ responded that there are pre- and post-test counselling while undergoing HTC whereas 93\% ( $n=$ 348) asserted that HTC is done in a private session where strict confidentiality was assured. Other items that revealed students' high score in HTC knowledge were: 92\% ( $n=346)$ showing that HTC is an entry point for treatment and support services for HIV/AIDS and 92\% $(n=343)$ correctly indicating that HTC helps one to know sero-status.

3.1.2 Student Nurses' Attitudes toward HTC Service

Student nurses' responses on their attitudes toward HTC services are presented in Table 3. Overall results indicate that majority, 95\% $(n=356)$ of the study participants have positive attitudes toward HTC.

Table 4 contains results on student nurses' attitudes toward HTC services. The results show 89\% $(n=332)$ prefer to receive HTC services from health professionals. Further, 43\% $(n=162)$ attested that HTC does not pre-dispose people to early sexual matters. Additionally, 52\% $(n=205)$ were willing to test for HIV if requested and lastly, 55\% $(n=205)$ of the respondents wanted HTC services to be integrated into youth programs such as STIs and family planning.

Table 1 Knowledge level of student nurses on HTC.

\begin{tabular}{lll}
\hline & Frequency & Percentage \\
\hline High knowledge & 317 & 85 \\
Moderate knowledge & 58 & 15 \\
\hline
\end{tabular}

Table 2 Students' knowledge on HTC service.

\begin{tabular}{|c|c|c|}
\hline & Correct (\%) & Incorrect (\%) \\
\hline HIV/AIDS testing and counselling reduces the risk for acquiring HIV/AIDS. & $336(90)$ & $39(10)$ \\
\hline HIV/AIDS testing and counselling is done at health facilities. & $335(89)$ & $40(11)$ \\
\hline HIV/AIDS testing and counselling helps to know one’s sero-status. & $343(92)$ & $32(8)$ \\
\hline HIV/AIDS testing and Counselling is done by trained health personnel at the hospital. & $336(90)$ & $39(10)$ \\
\hline HIV/AIDS testing and counselling helps an individual to acquire knowledge about HIV/AIDS. & $341(91)$ & $34(9)$ \\
\hline HIV/AIDS testing and counselling is done in a private session where strict confidentiality is assured. & $348(93)$ & $27(7)$ \\
\hline There is pre and post-test counselling while undergoing HIV/AIDS testing and counselling. & 350 (93) & $25(7)$ \\
\hline HIV/AIDS testing and counselling is an entry point for treatment and support services on HIV/AIDS. & $346(92)$ & $29(8)$ \\
\hline HIV/AIDS testing and counselling is for everybody. & $357(95)$ & $18(5)$ \\
\hline $\begin{array}{l}\text { In the provider initiated testing and counselling for pregnant women, there is no opt-out window for } \\
\text { the client. }\end{array}$ & $327(87)$ & $48(13)$ \\
\hline A positive HIV test result does not mean one has AIDS. & $331(88)$ & $44(12)$ \\
\hline
\end{tabular}


Table 3 Attitudes of student nurses towards HTC service.

\begin{tabular}{lll}
\hline & Frequency & Percentage \\
\hline Positive attitude & 356 & 95 \\
Negative attitude & 19 & 5 \\
\hline
\end{tabular}

Table 4 Attitudes of student nurses towards HTC service.

\begin{tabular}{|c|c|c|c|c|c|c|c|c|}
\hline & \multicolumn{2}{|c|}{ Strongly agree } & \multicolumn{2}{|c|}{ Agree } & \multicolumn{2}{|c|}{ Disagree } & \multicolumn{2}{|c|}{ Strongly disagree } \\
\hline & $\mathrm{F}$ & $\%$ & $\mathrm{~F}$ & $\%$ & $\mathrm{~F}$ & $\%$ & $\mathrm{~F}$ & $\%$ \\
\hline I prefer to receive HTC services from health professionals. & 332 & 88.5 & 38 & 10.1 & 2 & 0.5 & 3 & 0.8 \\
\hline $\begin{array}{l}\text { HIV testing and counselling does not pre-dispose } \\
\text { individuals to early sexual matters. }\end{array}$ & 162 & 43.2 & 117 & 31.2 & 62 & 16.5 & 34 & 9.1 \\
\hline $\begin{array}{l}\text { Students in health training colleges need to attend HIV } \\
\text { testing and counselling services. }\end{array}$ & 234 & 62.4 & 129 & 34.4 & 10 & 2.7 & 2 & 0.5 \\
\hline I am willing to test for HIV if requested. & 193 & 51.5 & 106 & 28.3 & 52 & 13.9 & 24 & 6.4 \\
\hline $\begin{array}{l}\text { HIV testing and counselling services should be provided } \\
\text { free of charge to students. }\end{array}$ & 315 & 84.0 & 51 & 13.6 & 6 & 1.6 & 3 & 0.8 \\
\hline $\begin{array}{l}\text { Students who are infected with HIV should be freely } \\
\text { provided with antiretroviral drugs. }\end{array}$ & 204 & 54.4 & 95 & 25.3 & 53 & 14.1 & 23 & 6.1 \\
\hline $\begin{array}{l}\text { HIV testing and counselling services should be provided in } \\
\text { the school. }\end{array}$ & 225 & 60.0 & 99 & 26.4 & 33 & 8.8 & 18 & 4.8 \\
\hline $\begin{array}{l}\text { HIV testing and counselling services should be integrated } \\
\text { into youth programs such as STIs and family planning. }\end{array}$ & 205 & 54.7 & 99 & 26.4 & 48 & 12.8 & 23 & 6.1 \\
\hline $\begin{array}{l}\text { HIV testing and counselling services should better be given } \\
\text { during youth activities like sports, drama and festival. }\end{array}$ & 192 & 51.2 & 106 & 28.3 & 54 & 14.4 & 23 & 6.1 \\
\hline $\begin{array}{l}\text { HIV testing and counselling services for young people } \\
\text { should be mixed with adults. }\end{array}$ & 84 & 22.4 & 97 & 25.9 & 130 & 34.7 & 64 & 17.1 \\
\hline
\end{tabular}

Table 5 Level of HTC utilisation service.

\begin{tabular}{lll}
\hline & $\begin{array}{l}\text { Yes } \\
\text { No. }(\%)\end{array}$ & $\begin{array}{l}\text { No } \\
\text { No. (\%) }\end{array}$ \\
\hline Ever use & $176(47)$ & $199(53)$ \\
Reasons for use & & $15(8)$ \\
Want to know status & $161(92)$ & $153(89)$ \\
Wanted to get married & $19(11)$ & \\
Reasons for non-use & & $175(88)$ \\
I don't see the need & $24(12)$ & $151(76)$ \\
I am afraid to know my status & $48(24)$ & $108(54)$ \\
I trust my self & $91(46)$ & $133(67)$ \\
I am not at risk & $66(33)$ & $156(78)$ \\
I don't trust the confidentiality of the results & $43(22)$ &
\end{tabular}

3.1.3 Student Nurses' Utilisation Level of HTC Service

Table 5 contains results on the student nurses level of HTC utilisation. Results reveal that 47\% $(n=176)$ of the respondents had ever utilised HTC while 53\% ( $n=199)$ have never utilised. Among those who utilised HTC services, their reasons given were to know their status, $92 \%(n=161)$ and for marriage $11 \%$ $(n=19)$. Among some of the reasons behind the non-use of HTC expressed by the respondents were: self-trust $46 \%(n=91)$ and the perception that they are not at risk $33 \%(n=66)$.

Table 6 contains results on Chi-Square analysis of the difference between respondents' class level and HTC knowledge, attitudes, and utilisation. The results on HTC knowledge expressed by the respondents 
Table 6 Class Level and HTC Knowledge, Attitude and Utilisation.

\begin{tabular}{|c|c|c|c|c|}
\hline & \multicolumn{2}{|c|}{ Class level of students } & \multirow{2}{*}{$\chi^{2}$} & \multirow{2}{*}{$p$-value } \\
\hline & 200 & 300 & & \\
\hline HTC Knowledge & & & 0.624 & 0.475 \\
\hline High & 149 (47\%) & 168 (53\%) & & \\
\hline Moderate & $24(41 \%)$ & 34 (59\%) & & \\
\hline HTC Attitudes & & & 2.334 & 0.158 \\
\hline Positive & $161(45 \%)$ & 195 (55\%) & & \\
\hline Negative & $12(63 \%)$ & 7 (37\%) & & \\
\hline HTC Utilisation & & & 14.263 & $0.000^{*}$ \\
\hline Yes & $63(36 \%)$ & $113(64 \%)$ & & \\
\hline No & $110(55 \%)$ & $89(45 \%)$ & & \\
\hline
\end{tabular}

* Significant.

based on class level reveal that majority of the level 300 students had high HTC knowledge 53\% ( $n=168)$ compared to $47 \%(n=149)$ of the level 200 students. The Chi-Square results show no statistically significant difference on class level and student nurses' knowledge about HTC services $\left(\chi^{2}[1, \mathrm{~N}=375]=0.624, p=\right.$ 0.475). Furthermore, more level 300 student nurses demonstrated positive attitudes toward HTC services compared to $45 \%$ ( $n=161)$ of level 200 students. There was no statistically significant difference of student nurses class level and their attitudes toward HTC services $\left(\chi^{2}[1, N=375]=2.334, p=0.158\right)$. Additionally, other results show the majority of the level 300 students, 64\% $(n=113)$ utilize HTC services compared to $36 \%(n=63)$ utilisation by the level 200 participants. There was a statistically significant difference in respondents' class level and HTC utilisation $\left(\chi^{2}[1, N=375]=14.263, p=0.000\right)$.

\section{Discussion}

The principal focus of this study was to ascertain the knowledge, attitudes and utilization of HIV testing and counseling services among student nurses of the public nursing and midwifery training colleges in the Central Region of Ghana. The findings show majority of student nurses have high knowledge on HTC, though few students provided incorrect responses to some of the issues. The high HTC knowledge recorded in this study is not surprising because students at level 200 and 300 students have theoretical and clinical exposure to HTC conditions and materials during that phase of their study [33]. Besides, the students also expressed high knowledge on the item that HTC is for everybody, implying that everybody is vulnerable to HIV/AIDS, hence the need for HTC as a preventive measure. It is reasonable to infer that participants in the current study may feel more capable of reducing their risk and other clients for contracting HIV by seeking for opportunities to know their status. According to Hall et al. [34], people who are aware of their status may potentially make behavioral changes and seek effective preventive measures, care or effectively manage the condition to reduce transmission. Conversely, inadequate health literacy, including low HIV related indices, may reduce the likelihood of engaging in preventative health behaviors [34].

The student nurses' high HTC knowledge is consistent with the findings from other studies on knowledge, attitudes and practices related to voluntary counseling and testing of HIV among college nurses, midwives and other healthcare professionals $[25,26$, 29, 35, 36]. However, drawing specific comparison with previous studies is difficult because those studies were conducted within diverse population groups and at different times. For example, previous current study participants may have heard of HIV and had their studies carried out more than a decade ago (e.g., in 
year 2000) and within certain geographical locations, where prevalence may have been low and respondents having minimal information about HIV. We assume that current study participants should be better informed because there is general increase in awareness throughout Ghana via various educational and promotional programmes at the grassroots level and a recent more open door approach adopted by key stakeholders (e.g., Ghana AIDS Commission; Ministry of Health; Ghana Education Service) and the mass media.

Findings from the study also show that majority of the students had positive attitudes toward HTC, with few expressing negative attitudes. The students' positive attitude may be because they are better placed, educated, and possibly more enlightened through their exposure during practicum (clinicals) related to health delivery, including people living with HIV/AIDS (PLWHA) and HTC services. The current finding is consistent with other studies, where a high intention score of the respondents to use HTC is explained by the Theory of Planned Behaviour (TPB) model [25, 26, 37]. Despite this finding, it has to be recognized that only average number of students, $52 \%(n=193)$ were willing to test for HIV if requested, implying that quite a number of these nursing trainees may be unwilling to seek and attend to information related to HIV prevention and diagnosis. Understandably, the fear of testing positive may account for students' unwillingness participation in HTC services. Students may therefore dislike HTC for the fear of the unknown and the potential stigma associated with testing positive. The somewhat unwilling attitude towards HTC by sections of students was also unrelated to their knowledge levels in the current study. We contend that this attitude towards HTC needs to be contextualized in today's contemporary society where choice is restricted to many aspects of social life regardless of one's knowledge level, particularly in the area related to sexual behavior. Contrarily, positive attitudes found in the present study contradict the other research findings [38]. We contend that some methodological limitations may be reasons for these inconsistencies.

HTC utilisation among the student nurses in the current study was low. The low HTC utilisation could be attributed to the students' lack of knowledge on the benefits of HTC services. Respondents own reasons for non-use such as: I trust myself, not at risk, lack of confidence in the testing process and fear of the unknown as indicated in Table 3 could have accounted for this finding. This current finding suggests that the act of utilizing HTC may mirror a normal complex behavioral process that is determined by diverse psychosocial factors and not merely the presence of adequate knowledge. For example, students who perceive to have low risk of being infected with HIV, may decide not to engage in HTC services. Similarly, those with fear of HIV positive results, and the potential stigmatisation as well as discrimination may not avail themselves for HTC [39, 40]. Additionally, the low utilization of HTC services recorded by the students could be likened to the healthcare utilisation model which states that utilization of healthcare services is dependent on predisposing enabling and need factors. The model emphasizes on one's health beliefs and health seeking behavior, cultural beliefs, social networks, income, perceived health status and severity of a disease condition [41]. Thus, if an individual perceives not to be at risk of HIV, possibly due to lifestyle or does not have a supportive social network of HTC, going for HTC might not be considered essential by such a person [41]. It also possible that lack of access to carefully designed counseling programmes could be responsible for the low usage of HTC services among trainee students [42]. The current low HTC utilisation results corroborate with other studies conducted in Ghana and parts of Sub-Saharan Africa among health professional students [25, 26, 43-45].

There was a statistically significant difference between educational level and HTC utilization of 
study participants. The difference observed could mean that students who are in school for a considerable time and at a higher level are more exposed to more curricular and clinical exposure to health delivery processes, including HTC related issues than those at the lower level of education. This assertion can be observed in the results, where more (above average) level 300 than 200 students, 53\% had high HTC knowledge, 55\% exhibited positive attitudes toward HTC services, and 64\% utilized HTC services. By inference, the higher a person's level of education and exposure to HTC related protocols, the more likelihood the adoption and utilization of HTC services.

\subsection{Practical Implications}

The high knowledge exhibited in this study trainees is positive for onward transmission or transfer to clients in their future work engagement as Ghana is poised to halt new HIV infections by 2020 [46]. Further, students are more likely to guide themselves by practicing safe sex and relationship to avoid either contracting HIV or adopting proper management measures. Additionally, students' awareness on where HTC is conducted (designated health centers) could impact on their confidence to undertake HTC services. The premise is on the assumption that these HTC services would be conducted at a secured place, where confidentiality would be assured and potentially increase students' personal uptake and the general public HTC utilisation [36]. Hence, inadequate health literacy, including low HIV knowledge, may decrease the likelihood of engaging in preventative health behaviors.

Another implication is that positive attitude could be a motivation and expression of confidence in the ability of HTC services for prevention, care and treatment of HIV/AIDS. This is intrinsically beneficial to the professional nurse who should serve as a role model to prescribe HTC services to clients and augment the quest to curb the spread of the HIV/AIDS pandemic. This positive attitude of the student nurses could be good for the future healthcare delivery in Ghana as study participants may serve as ambassadors of HTC campaigns nation-wide. One can also assume that the current curriculum of the pre-service nurses should act as good influencing agent that should help students appreciate and understand their own risk for HIV [33, 35]. The somewhat negative attitudes displayed by few respondents (5\%) mean that some trainee nurses might have stigmatizing or refraining attitudes toward HTC services, a scenario that may impact negatively on their commitment and initiatives toward HTC services as future nurses.

The potential future health professionals, who perhaps should be in the forefront in curbing the HIV/AIDS menace, were not much keen on HTC utilization. This means that educational programmes for trainee health professionals must address specific issues on the need for clear protocols. These explicit protocols must cover indicators such as anonymity, confidentiality, and specific guidelines for the care and management of HTC related protocols. The low utilisation of HTC is that much has to be done on health system operations and care delivery toward nursing and midwifery training as knowledge alone may not necessarily bring about behavior change. The students' failure to make use of HTC is likely to lead to missing opportunities for early diagnoses, care, treatment, and support services for primary, secondary or tertiary prevention modes. Their non-use may trigger HIV/AIDS related stigmas and show disapproval to PLWHA [47]. Also, respondents' reasons for non-use of HTC: trust self, not at risk and do not see the need, imply they may be having low perceived and personal risk assessment that might be detrimental to their health and the general public. This will pose a health threat to people into conjugal relationships in the future.

\subsection{Limitations}

There are few limitations that may bias findings in 
the current study. The design of the questionnaire might not reflect all aspects of students' knowledge, attitudes and utilisation of HTC or restrict students on the expression of their opinions on salient matters or might have misunderstood some of the questions. Therefore, questionnaire lacks the power to detect all misunderstandings despite the presence of a team of officials. Questions on sensitive issues like HIV/AIDS might be prone to biases, could affect the reliability and validity of measures such as behavioral terminologies, recall biases, self-presentation or confidentiality concern resulting from stigmatization associated with a reported behavior [48]. To minimize this effect, we ensured full anonymity and confidentiality of study participants. The cross-sectional design of the study prohibits inference of causality among the study variables. Therefore, they do not allow predictive or causal interpretations of the findings.

\section{Conclusion}

Nursing trainees' knowledge, attitudes and utilisation of HTC services would provide vital gateway to help curb the HIV epidemic in Ghana through the identification of a well-defined system protocols for diagnoses, care, and management of HIV/AIDS. Therefore, HTC protocols would help bridge the risk through effective prevention and resources that might minimize the possibility of future infection. Addressing barriers to testing requires the importance of understanding HIV knowledge, promoting positive attitudes toward HIV testing experience and related health behaviors that would be good indicators for future healthcare delivery of Ghana. Specifically, current findings of this study should improve HIV testing and linkage to care interventions through specific educational strategies and developing measures to evaluate HIV related knowledge, attitudes and utilization of HTC. Future research should compare psychosocial determinants that may influence knowledge, attitudes and HTC services across trainee nurses from different regions of
Ghana for more definitive strategies through outcome evaluation. This research could use longitudinal approaches to show causal and directional inferences to enhance understanding of the processes surrounding HTC services.

\section{Conflict of Interest}

The authors declare no conflict of interest in the conduct of this research.

\section{Contribution}

FS and BOA made substantial contribution to onsite data collection and management, analysis and interpretation of data, and writing of the initial draft of the manuscript. TH, JEH, and TS also substantially contributed to the study conception, design, interpretation of data, and reviewed the final version of the manuscript. All the authors proof read the final version of the manuscript for its intellectual content, approved the final version to be submitted for publication, and agreed to be accountable for all aspects of the work.

\section{Acknowledgements}

The authors thank Emelia and Brew Butler research foundation and the School of Graduate Studies, University of Cape Coast, Ghana, and Neurocognition and Action-Biomechanics Research Group, Bielefeld University, Germany for providing financial support for this research.

\section{References}

[1] Tanye, V. K. "Exploring the Attitude, Knowledge and Experiences of the Youth towards HIV Counseling and Testing.” Doctoral dissertation, University of Ghana.

[2] Tsegay, G., Edris, M., and Meseret, S. 2013. “Assessment of Voluntary Counseling and Testing Service Utilization and Associated Factors among Debre Markos University Students, North West Ethiopia: A Cross-Sectional Survey in 2011.” BMC Public Health 13 (1): 243.

[3] Henry, J. 2015. "The Global HIV/AIDS Epidemic. World Population Data Fact Sheet 2015.” Kaiser Family Foundation. Retrieved from http:/files.kff. 
org/attachment/fact-sheet-the-global-hivaids-epidemic.

[4] UNAIDS. 2016. Global AIDS Update: UNAIDS Report on the Global AIDS Epidemic. Geneva, Switzerland. 2016. Accessed 24th September, 2016 from http://aidsinfo.unaids.org/.

[5] NACP. HIV/AIDS in Ghana (3rd. ed.). MOH, National AIDS Control Unit, Accra. 2001, Retrieved from http://www.policyproject.com/pubs/countryreports/gha_a im3rded.pdf.

[6] Ghana AIDS Commission. Country aids response progress report, January, 2012-December, 2013. Accra, Ghana, 2014.

[7] Ghana AIDS Commission. Country aids response progress report, January, 2013-December, 2014. Accra, Ghana, 2015.

[8] SADC. 2010. Assessment Report on the Status of HIV Testing and Counselling Policies in the SADC Region. Retrieved on 20th September, 2016 from http://www.sadc.int.

[9] Kamenga, M. C., Sweat, M. D., De Zoysa, I., Dallabetta, G., Coates, T. J., Grinstead, O. A., et al. 2000. “The Voluntary HIV-1 Counseling and Testing Efficacy Study: Design and Methods.” AIDS and Behavior 4 (1): 5-14.

[10] Coates, T. J. 2000. "Efficacy of Voluntary HIV-1 Counselling and Testing in Individuals and Couples in Kenya, Tanzania, and Trinidad: A Randomised Trial.” Lancet (British edition) 356 (9224): 103-12.

[11] Kamb, M. L., Fishbein, M., Douglas, J. M., Rhodes, F., Rogers, J., Bolan, G., and Kent, C. 1998. "Efficacy of Risk-Reduction Counseling to Prevent Human Immunodeficiency Virus and Sexually Transmitted Diseases: A Randomized Controlled Trial.” JAMA 280 (13): 1161-7.

[12] Weinhardt, L. S., Carey, M. P., Johnson, B. T., and Bickham, N. L. 1999. "Effects of HIV Counseling and Testing on Sexual Risk Behavior: A Meta-Analytic Review of Published Research, 1985-1997.” American Journal of Public Health 89: 1397-404.

[13] Samayoa, B., Anderson, M. R., O’Sullivan, L. F., Patricia, K., Pacheco, A., Matos, A., et al. 2010. "Does HIV VCT Reduce Risk Behaviours? An Observational Study in Guatemala City.” Current HIV Research 8 (2): 121-6.

[14] ECDC. 2010. "HIV Testing: Increasing Uptake and Effectiveness in the European Union. Stockholm.” Retrieved from http://www.ecdc.europa.eu/en/publications/Publications/1 01129_GUI_HIV_testing.pdf.

[15] Summers, T., Spielberg, F., Collins, C., et al. 2000. "Voluntary Counselling, Testing and Referral for HIV: New Technologies, Research Findings Create Dynamic Opportunities.” Journal of Acquired Immune Deficiency Syndrome 25 (Suppl 2): S128-35.
[16] UNAID. 2004. Report on the Global AIDS Epidemic: Executive Summary. Geneva, Switzerland.

[17] Setswe, G. 2006. "Systematic Reviews of Behavioural Interventions for Reducing the Risk of HIV and AIDS: Are We Getting the Evidence.” SAHARA Journal 3 (2): 477-81.

[18] Ghana Statistical Service (GSS), Ghana Health Service (GHS), and ICF Macro. Ghana Demographic and Health Survey 2008. Accra, Ghana: GSS, GHS, and ICF Macro. 2009, $\quad$ Retrieved from https://www.dhsprogram.com/pubs/pdf/FR221/FR221[13 Aug2012].pdf.

[19] Pronyk, P. M., Kim, J. C., Makhubele, M. B., et al. 2002. "Introduction of Voluntary Counselling and Rapid Testing for HIV in Rural South Africa: From Theory to Practice.” AIDS Care 14: 859-65.

[20] Durkin, A. 2004. "Comfort Levels of Nursing Students Regarding Clinical Assignment to a Patient with AIDS.” Nursing Education Perspectives 25 (1): 22-5.

[21] Reis, C., Heisler, M., Amowitz, L. L., Moreland, R. S., Mafeni, J. O., Anyamele, C., and Iacopino, V. 2005. "Discriminatory Attitudes and Practices by Health Workers toward Patients with HIV/AIDS in Nigeria." Public Library of Science Medicine 2 (8): 246.

[22] Bektas, H. A., and Kulakac, O. 2007. "Knowledge and Attitudes of Nursing Students toward Patients Living with HIV/AIDS (PLHIV): A Turkish Perspective AIDS Care." Psychological and Socio-Medical Aspects of AIDS/HIV 19 (7): 888-94.

[23] Eriksson, L., and Grundin, D. R. 2010. "Nursing Students' Knowledge and Attitudes towards People with HIV/AIDS: A Quantitative Study at MIOT College of Nursing, India.” Retrieved from http://www.diva-portal. org/smash/get/diva2:406047/FULLTEXT01.pdf.

[24] Röndahl, G., Innala, S., and Carlsson, M. 2003. "Nursing Staff and Nursing Students' Attitudes towards HIV-Infected and Homosexual HIV-Infected Patients in Sweden and the Wish to Refrain from Nursing.” Journal of Advanced Nursing 41 (5): 454-61.

[25] Charles, M. P., Kweka, J. E., Mahande, M. A., Barongo, L. R., Shekalaghe, S., Nkya, M. H., et al. 2009. "Evaluation of Uptake and Attitude to Voluntary Counseling and Testing among Health Care Professional Students in Kilimanjaro Region, Tanzania.” Bio Medical Council and Public Health 9 (1): 128.

[26] Edem, G. T., Laar, A. S., and Ahenkan, A. 2015. "Knowledge and Attitudes of Nursing Students on Voluntary HIV Counselling and Testing in Ghana: Implication for Nursing Education and Policy.” $A R C$ Journal of Nursing and Healthcare (AJNH) 1 (1): 38-45.

[27] Hara, J. R. 2008. "Perceptions and Attitudes of First Year Student Nurses towards Voluntary HIV Counselling and 
Testing at the Western Cape College of Nursing.” Master of public health, University of the Western Cape, South Africa. $\quad$ Retrieved from http://etd.uwc.ac.za/xmlui/bitstream/handle/11394/2412/ Hara_MPH_2007.pdf?sequence=1.

[28] Tarwireyi, F., and Majoko, F. 2003. "Health Workers' Participation in Voluntary Counseling and Testing in Three Districts of Mashona-land East Province, Zimbabwe." Central Africa Journal of Medicine 49 (5): 58-65.

[29] Chris-Koka, E. 2012. "Factors Affecting HIV Counselling and Testing among Tertiary Students in the Ho Municipality.” Master's Dissertation, University of Ghana, Legon. Retrieved from University of Ghana http://ugspace.ug.edu.gh.

[30] Krejcie, R. V., and Morgan, D. W. 1970. "Table for Determining Sample Size from a Given Population.” Educational and Psychological Measurement 30: 607-10.

[31] Creswell, J. W. 2009. Research Design: Qualitative, Quantitative, and Mixed Methods Approaches (3rd ed.). California: Sage Publications.

[32] Tabachnick, B. G., and Fidell, L. S. 2007. Using Multivariate Statistics (5th ed.). Boston, MA: Allyn \& Bacon.

[33] NMC. 2015. Curriculum for Registered General Nursing and Midwifery Programme. NMC, Accra.

[34] Hall, H. I., An, Q., Tang, T., Song, R., Chen, M., Green, T., et al. 2015. "Prevalence of Diagnosed and Undiagnosed HIV Infection-United States, 2008-2012.” MMWR Morb Mortal Wkly Rep. 64 (24): 657-62.

[35] Hamukangandu, L., Fleming, L. C., Felix, S., and Jacobson, K. H. 2016. "Knowledge, Attitudes, and Practices Related to Voluntary Counselling and Testing for HIV among Nursing Students in Zambia." Sierra Leone Journal of Biomedical Research 8 (2): 1-8.

[36] Obiajulu, A. C. 2009. "Knowledge, Attitude and Practice of Voluntary Counseling and Testing (VCT) for HIV/AIDS amongst the Health Professionals in Umpumulo Hospital, Mapumulo, Ilembe District, Kwazulu-Natal Province.” Doctoral thesis, University of Limpopo. Retrieved from http://ulspace.ul.ac.za/handle/10386/186/discover?filterty pe_0=subject\&filter_0=HIV+AIDS\&filter_relational_ope rator_0 $=$ equals\&filtertype $=$ author\&filter_relational_oper ator=equals\&filter=Obiajulu\%2C+Anthony.

[37] Abamecha, F., Godesso, A., and Girma, E. 2013. "Intention to Voluntary HIV Counseling and Testing (VCT) among Health Professionals in Jimma Zone, Ethiopia: The Theory of Planned Behavior (TPB) Perspective.” Biomedical Council for Public Health 13: 140.

[38] Swenson, R. R., Rizzo, C. J., Brown, L. K., Vanable, P.
A., Carey, M. P., Valois, R. F., et al. 2010. "HIV Knowledge and Its Contribution to Sexual Health Behaviors of Low-Income African American Adolescents.” J Natl Med Assoc 102 (12): 1173-82. doi:10.1016/S0027-9684(15)30772-0.

[39] Ma, W., Detels, R., Feng, Y., Wu, Z., Shen, L., Li, Y., et al. 2007. "Acceptance of and Barriers to Voluntary HIV Counselling and Testing among Adults in Guizhou Province, China.” AIDS (London, England) 21 (Suppl 8): S129.

[40] Iliyasu, Z., Abubakar, I. S., Kabir, M., and Aliyu, M. H. 2006. "Knowledge of HIV/AIDS and Attitude towards Voluntary Counseling and Testing among Adults." Journal of the National Medical Association 98 (12): 1917.

[41] Andersen, R., and Newman, J. F. 1973. "Societal and Individual Determinants of Medical Care Utilization in the United States.” Milbank Memorial Fund Quarterly Health and Society 51: 95-124.

[42] Kyaligonza, E., and Miiro, M. 2004. International Conference on AIDS (Bangkok, Thailand). July 11-16, 2004, 15: abstract No.WePeD6455.

[43] Peltzer, K., Mpofu, E., Baguma, P., and Lawal, B. 2002. "Attitudes towards HIV Antibody Testing among Students from Four African Countries.” International Journal for the Advancement of Counseling 3 (24).

[44] Ikechebelu, I. J., Udigwe, G. O., Ikechebelu, N., and Imoh, L. C. 2006. “The Knowledge, Attitude and Practice of Voluntary Counselling and Testing (VCT) for HIV/AIDS among Undergraduates in a Polytechnic in Southeast, Nigeria.” Nigerian Journal of Medicine 15 (3): 245-9.

[45] Irungu, T. K., Varkey, P., Cha, S., and Patterson, P. M. 2008. "HIV Voluntary Counseling and Testing in Nakuru, Kenya: Findings from a Community Survey." HIV Medicine 9: 111-7.

[46] Ghana Statistical Service (GSS), Ghana Health Service (GHS), and ICF International. Ghana Demographic and Health Survey 2014. Rockville, Maryland, USA: GSS, GHS, and ICF International. 2015. Retrieved from http://www.statsghana.gov.gh/docfiles/publications/2014 \%20GDHS\%20\%20Report.pdf.

[47] Kalichman, S. C., and Simbayi, L. C. 2003. "HIV Testing Attitudes, Aids Stigma, Voluntary HIV Counselling and Testing in a Black Township in Cape Town, South Africa." Sexually Transmitted Infections 79: 442-7.

[48] Hagan Jr., J. E. and Menyanu, E. 2013. "In-School Children's Awareness of the Concept of HIV/AIDS and the Likely Risky Behaviors among Selected Basic Schools in the Jukwa Circuit of the Central Region of Ghana.” Journal of Counselling, Education and Psychology 3 (1): 100-10. 